\title{
Ethanol Ablation of Ranulas: Short-Term Follow-Up Results and Clinicoradiologic Factors for Successful Outcome
}

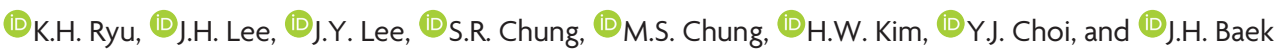

\begin{abstract}
BACKGROUND AND PURPOSE: Surgical excision of an affected sublingual gland for treatment of a ranula can carry a potential of a nerve damage or postoperative complications. However, there have been little studies about effective minimally invasive therapeutic method, yet. Our aim was to evaluate the efficacy and safety of ethanol ablation of ranulas and the clinicoradiologic factors that can predict outcome.
\end{abstract}

MATERIALS AND METHODS: This retrospective study evaluated 23 patients with ranulas treated by percutaneous ethanol ablation. Treatment outcome was assessed in 20 patients followed for at least 6 months. The duration of symptoms before ethanol ablation, pretreatment volume, and parapharyngeal extension on sonography and/or CT were correlated with the outcome. The Mann-Whitney $U$ test and Fisher exact test were used for comparison of the factors according to the outcome.

RESULTS: The study evaluated 14 males and 9 females with a median age of 26 years (range, 3-41 years). Among 20 patients who were followed for at least 6 months (median, 20 months; range, 6-73 months), 9 patients (45\%) demonstrated complete disappearance of the ranulas and 11 (55\%) showed an incomplete response. When the patients were divided according to the duration of symptoms before ethanol ablation, the complete response rate was significantly higher in patients with $\leq 12$ months of symptoms (73\%, $8 / 11)$ than that in others $(11 \%, 1 / 9)(P=.010)$. Pretreatment volume and parapharyngeal extension were not significantly different between the 2 groups.

CONCLUSIONS: Ethanol ablation is a safe and noninvasive treatment technique for ranulas with a significantly better outcome in patients with $\leq 12$ months of symptoms. Therefore, it could be considered an alternative nonsurgical approach for ranulas with recent onset of symptoms.

ABBREVIATION: EA = ethanol ablation

A ranula is a pseudocyst or mucous-retention cyst that arises from leakage of saliva from the sublingual or minor salivary gland. ${ }^{1}$ Ranulas have traditionally been surgically treated by excision of the affected sublingual gland with or without the excision of the ranula. ${ }^{1,2}$ Surgical excision is a definitive treatment with

Received December 27, 2016; accepted after revision May 9, 2017.

From the Department of Radiology and Research Institute of Radiology (K.H.R., J.H.L., J.Y.L., S.R.C., M.S.C., H.W.K., Y.J.C., J.H.B.), University of Ulsan College of Medicine, Asan Medical Center, Seoul, Republic of Korea; Department of Radiology (K.H.R.), Gyeongsang National University School of Medicine and Gyeongsang National University Changwon Hospital, Changwon, Republic of Korea; Department of Radiology (J.Y.L.), Soonchunhyang University College of Medicine, Soonchunhyang University Bucheon Hospital, Bucheon, Republic of Korea; and Department of Radiology (M.S.C.), Chung-Ang University College of Medicine, Chung-Ang University Medical Center, Seoul, Republic of Korea.

Please address correspondence to Jeong Hyun Lee, MD, PhD, Head \& Neck Division, Department of Radiology and Research Institute of Radiology, University of Ulsan College of Medicine, Asan Medical Center, 88 Olympicro-43-gil, Songpa-gu, 05505, Seoul, Republic of Korea; e-mail: jeonghlee@amc.seoul.kr

http://dx.doi.org/10.3174/ajnr.A5292 very low recurrence rates, ranging from $0 \%$ to $2 \%{ }^{3,4}$ However, excision of the sublingual gland can be technically difficult and carries a potential risk of damage to the surrounding vital structures, including the lingual nerve and the submandibular duct, with postoperative complication rates ranging from $11 \%$ to $29 \% .^{3,4}$ Therefore, there is a need for a nonsurgical minimally invasive treatment of ranulas.

Among chemical ablation agents, picibanil (OK-432; Chugai Pharmaceutical Co, Tokyo, Japan) has been most commonly reported for minimally invasive treatment of ranulas. ${ }^{1,3,5-9}$ Intracystic injection of OK-432 is safe without serious complications, but the recurrence rate is relatively high, from $23 \%$ to $48 \%$. $^{1,3,8}$ Therefore, more effective sclerosing agents are necessary for successful minimally invasive treatment of ranulas.

Ethanol is an effective sclerosing agent ${ }^{2,10}$; its effects include instantaneous cellular dehydration and protein denaturation that result in the clumping of blood cells and vessel wall necrosis, followed 
by thrombosis and occlusion of vessels. ${ }^{10,11}$ It has been reported that ethanol ablation (EA) is effective and safe for the treatment of benign cervical cystic lesions, including cystic thyroid nodules, thyroglossal duct cysts, and lymphatic malformations. ${ }^{12-18}$

To the best of our knowledge, no previous studies have examined the treatment efficacy and safety of EA for ranulas. The purpose of this study was to evaluate these features and the clinicoradiologic factors that can predict its outcome in a retrospective cohort.

\section{MATERIALS AND METHODS \\ Patients}

This study was approved by the institutional review board of our institution (University of Ulsan College of Medicine, Asan Medical Center), and written informed consent for EA was obtained from all patients before the procedure. We searched the electronic medical records from 2010 to 2015 to find consecutive patients treated with EA after confirmation of a ranula by aspiration of thick mucus fluid.

\section{Preprocedural Evaluation}

In addition to basic demographic data, we also evaluated the duration of symptoms before EA and the history of prior treatment. In all patients, the preprocedural sonography was performed by 1 radiologist (J.H.L., with 14 years of experience in performing sonography-guided procedures of the head and neck regions) with 1 of 2 sonographic systems: an Acuson S3000 Ultrasound System (Siemens, Erlangen, Germany) or an EUB-7500 unit (Hitachi Medical Systems, Tokyo, Japan) equipped with a linear, high-frequency probe (6-18 or 5-14 MHz). The sonographic examination was performed to determine the location of the ranula, the presence of direct contact with the sublingual gland, and the volume of the cystic lesion. If available, contrast-enhanced CT was also evaluated for the aforementioned imaging findings.

\section{Ethanol Ablation and Follow-Up}

All EAs were performed by the same radiologist (J.H.L), with the patient in a supine position and the neck extended under local anesthesia with $2 \%$ lidocaine. Moderate sedation was used for an uncooperative child. A 16- to 18-gauge needle was inserted into the ranula to aspirate the thick mucus fluid with a $30-\mathrm{mL}$ syringe via a short connector. Internal debris and residual thick mucus material were cleared by irrigation with saline. Before the ethanol injection, 2\% lidocaine was injected and retained inside the pseudocyst for 30 seconds to check for any sensory or motor changes induced by the lidocaine anesthesia and for pain control. After re-aspiration of the lidocaine, $100 \%$ ethanol was slowly injected into the ranula. The amount injected was determined to be approximately $50 \%$ of the volume of the aspirate. The injected ethanol was completely re-aspirated after remaining in the ranula for 10 minutes.

Patients were re-evaluated at 1-, 6-, and 12-month intervals after EA and then annually with sonography and/or CT examination to check for the recurrence of the lesion or of symptoms. EA was reperformed if there was a cystic cavity of $>50 \%$ of the initial volume at the 1-month follow-up or if there was a recurrence of a cystic lesion with an estimated volume of $>1-2 \mathrm{~mL}$ during the
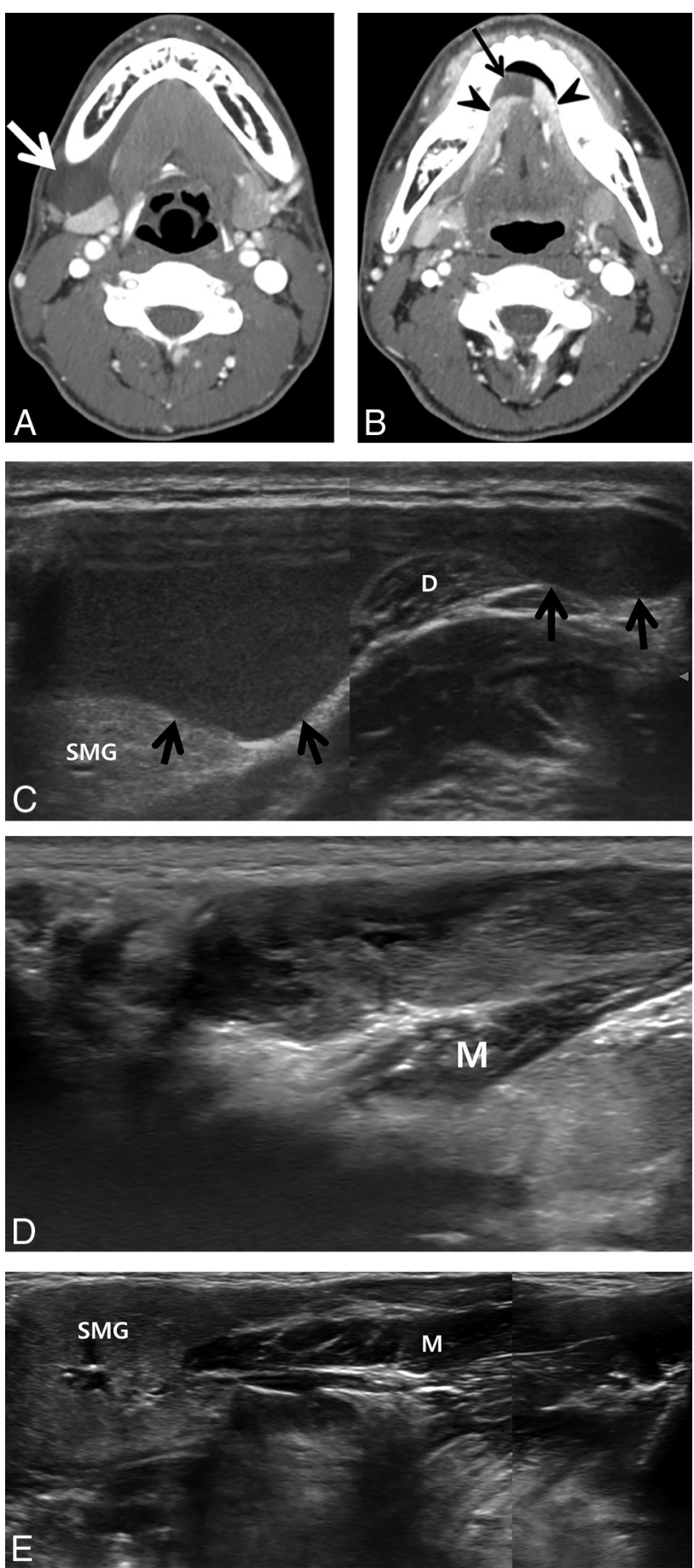

FIG 1. A 19-year-old man with a plunging ranula in the right submandibular space developed 1 month previously. $A$ and $B$, Pretreatment contrast-enhanced axial CT images. $A$, Axial CT image shows a well-defined cystic mass in the right submandibular (thick arrow) space. $B$, Another CT image demonstrates the cystic mass continuing into the sublingual space (thin arrow), showing direct contact with bilateral sublingual glands (arrowheads). C, Pretreatment oblique sonogram shows a fluid collection with internal debris in the right submandibular space (arrows). D, Sonogram 1 month after 2 sessions of ethanol ablation in the same plane as $C$ shows complete disappearance of the ranula in the submandibular space. $E, A$ sonogram 12 months after $D$ in the same plane shows complete disappearance of the ranula in the submandibular and sublingual spaces. SMG indicates submandibular gland; M, mylohyoid muscle; $\mathrm{D}$, anterior belly of the digastric muscle. 

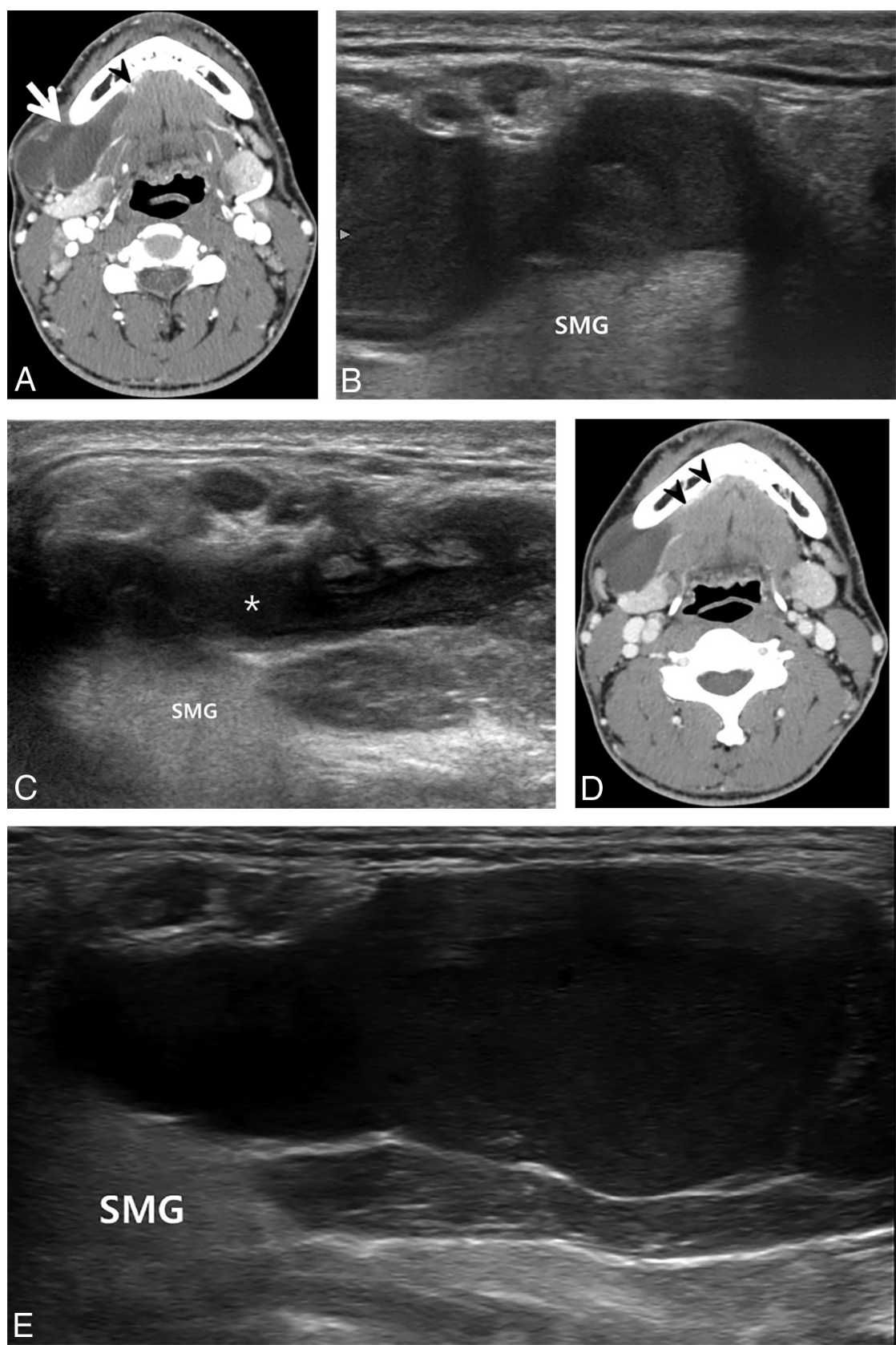

FIG 2. A 32-year-old man with a plunging ranula in the right submandibular space for the past 16 months. A, Pretreatment contrast-enhanced axial CT image shows a well-defined lobulated cystic mass (arrow) in the right submandibular space showing direct contact with the herniated right sublingual gland (arrowhead). B, Pretreatment oblique sonogram shows a fluid collection in the right submandibular space. C, Sonogram 1 month after ethanol ablation demonstrates the remaining fluid in the same space (asterisk). D, Contrast-enhanced axial CT image 34 months after ethanol ablation shows the cystic mass in the right submandibular space, adjacent to the herniated right sublingual gland (arrowheads). E, Oblique sonogram 34 months after ethanol ablation also demonstrates a cystic mass in the same space, showing an increase in size compared with $C$. SMG indicates submandibular gland.

remainder of the follow-up period. However, none of the patients were treated with EA $>3$ times.

\section{Statistical Analysis}

The final treatment outcome was assessed at the last follow-up as a complete response (complete disappearance of the cystic cavity), an incomplete response (decreased volume of the cystic cavity), or no response (unchanged cystic cavity). Treatment re- sponse was only assessed in patients who were followed up for at least for 6 months after the last EA. We tested for an association between the final outcome and the duration of symptoms before EA, pretreatment volume, and extension to the parapharyngeal space on sonography or CT with a Mann-Whitney $U$ test and Fisher exact test.

All statistical analyses were performed with the SPSS, Version 12.0 (IBM, Armonk, New York). The Mann-Whitney $U$ test and Fisher exact test were used for comparison of the factors according to the outcome. A $P$ value $<.05$ was considered statistically significant.

\section{RESULTS}

Twenty-three patients were treated with EA, including 14 males and 9 females with a median age of 26 years (range, 3-41 years). Among the 23 patients, 19 had a plunging ranula continuous with a herniated sublingual gland in the submandibular space, 2 had simple ranulas, and 2 had ranulas with direct contact with the submandibular gland instead of the sublingual gland.

Seven of the 23 patients had a history of prior treatment, including 5 patients who had been treated with chemical ablation with OK-432 and 2 patients who had been surgically treated (one via intraoral excision of the ranula and the other via excision of the submandibular gland). The number of EA sessions was 1 in 11 patients, 2 in 10 patients, and 3 in 2 patients. There were no procedure-related complications in any patients.

Twenty of the 23 patients were followed up for at least 6 months after EA and were assessed for the final treatment outcome at the last follow-up. The median follow-up time after the last EA was 20 months (range, 6-73 months). Nine of $20(45 \%)$ patients demonstrated complete disappearance of the ranula (Fig 1), but 11 (55\%) demonstrated an incomplete response (Fig 2). Four of 11 patients with an incomplete response underwent surgical excision of the sublingual gland after recurrence. The clinicoradiologic characteristics and outcome of all patients are summarized in the Table.

Among the 9 patients with complete response, EA was performed once in 7 patients and twice in 2 patients. Both patients with simple ranulas showed a complete response after a single session of EA. Among the 11 patients with incomplete responses, the number of EA sessions was 1 in 2 patients, 2 in 7 patients, and 
Summary of clinicoradiologic factors and outcome after ethanol ablation

\begin{tabular}{|c|c|c|c|c|c|c|c|c|c|c|c|c|}
\hline \multirow[b]{2}{*}{ No } & \multirow[b]{2}{*}{ Sex } & \multirow[b]{2}{*}{ Age (yr) } & \multicolumn{2}{|c|}{ Prior Treatment } & \multirow[b]{2}{*}{ Symptom Duration (mo) } & \multicolumn{3}{|c|}{$\begin{array}{c}\text { Pretreatment } \\
\text { Characteristics of Ranulas }\end{array}$} & \multirow{2}{*}{$\begin{array}{l}\text { No. of } \\
\text { EAs }\end{array}$} & \multirow[b]{2}{*}{ Outcome } & \multirow[b]{2}{*}{ F/U Duration (mo) } & \multirow[b]{2}{*}{ Imaging $F / U$} \\
\hline & & & OK-432 & Surgery & & Type & PPS Extension & Volume (mL) & & & & \\
\hline 1 & $M$ & 22 & Yes & & 1 & Plunging & Yes & 4.5 & 1 & Complete & 73 & US \\
\hline 2 & $\mathrm{~F}$ & 7 & & & 1 & Plunging & Yes & 10.5 & 1 & Complete & 25 & US \\
\hline 3 & $M$ & 19 & & & 1 & Plunging & & 15.0 & 2 & Complete & 13 & US \\
\hline 4 & $\mathrm{~F}$ & 34 & & SLG excision & 2 & Simple & & 7.1 & 1 & Complete & 27 & - \\
\hline 5 & $\mathrm{~F}$ & 18 & & & 2 & Plunging & & 9.4 & 1 & Complete & 15 & US \\
\hline 6 & $\mathrm{~F}$ & 32 & & & 2 & Simple & & 6.5 & 1 & Complete & 19 & US \\
\hline 7 & $M$ & 27 & & & 3 & Plunging ${ }^{a}$ & Yes & 30.0 & 2 & Complete & 29 & US \\
\hline 8 & M & 3 & & & 8 & Plunging & & 3.0 & 1 & Complete & 6 & US \\
\hline 9 & $M$ & 28 & & & 12 & Plunging & Yes & 19.6 & 1 & Complete & 32 & US \\
\hline 10 & $M$ & 32 & & & 16 & Plunging & & 30.0 & 1 & Incomplete & 34 & US/CT \\
\hline 11 & $\mathrm{~F}$ & 25 & & & 2 & Plunging & & 20.0 & 2 & Incomplete & 8 & US \\
\hline 12 & $M$ & 23 & & & 4 & Plunging & Yes & 8.8 & 2 & Incomplete & 21 & US \\
\hline 13 & $\mathrm{~F}$ & 31 & Yes & & 7 & Plunging & Yes & 3.1 & 1 & Incomplete & 32 & US \\
\hline 14 & $\mathrm{~F}$ & 28 & & & 12 & Plunging & Yes & 14.4 & 3 & Incomplete & 7 & US \\
\hline 15 & $M$ & 17 & & & 12 & Plunging & Yes & 8.2 & 1 & Incomplete & 15 & - \\
\hline 16 & $M$ & 23 & & & 13 & Plunging & & 3.3 & 2 & Incomplete & 6 & US \\
\hline 17 & $M$ & 38 & Yes & SMG excision & 36 & Plunging & & 45.1 & 2 & Incomplete & 46 & US \\
\hline 18 & $M$ & 41 & & & 36 & Plunging & & 2.1 & 2 & Incomplete & 22 & US \\
\hline 19 & $\mathrm{~F}$ & 13 & & & 42 & Plunging ${ }^{a}$ & & 8.9 & 2 & Incomplete & 16 & US/CT \\
\hline 20 & $M$ & 37 & Yes & & 240 & Plunging & & 9.4 & 2 & Incomplete & 8 & US \\
\hline 21 & $M$ & 27 & Yes & & 13 & Plunging & Yes & 27.0 & 3 & Incomplete & 1 & US/CT \\
\hline 22 & $\mathrm{~F}$ & 32 & & & 13 & Plunging & Yes & 9.0 & 1 & Incomplete & 1 & US \\
\hline 23 & $M$ & 16 & & & 24 & Plunging & & 11.0 & 2 & Complete & 1 & US \\
\hline
\end{tabular}

Note:-F/U indicates follow-up; PPS, parapharyngeal space; SLG, sublingual gland; SMG, submandibular gland; US, ultrasound.

a The ranula was in contact with the hilum of the submandibular gland.

3 in 2 patients, which was significantly different from that in those with complete responses $(P=.026)$.

When the clinical and radiologic factors were compared between the complete and incomplete response groups, the duration of symptoms before EA was significantly shorter in the complete response group (median, 2 months; range, 1-12 months) than in the incomplete response group (median, 13 months; range, $2-240$ months; $P=.001$ ). When the patients were divided according to the duration of symptoms, the complete response rate was significantly higher in patients with $\leq 12$ months of symptoms $(73 \%, 8 / 11)$ than in those with $>12$ months of symptoms $(11 \%, 1 / 9)(P=.010)$. The complete response rate was not significantly different between pediatric $(3 / 5,60 \%)$ and nonpediatric $(6 / 15,40 \%)$ patients $(P>.05)$. The other factors, including pretreatment volume and the presence of a parapharyngeal extension, were not significantly different between the complete (median, $9 \mathrm{~mL}$; range, $3-30 \mathrm{~mL} ; n=4,44 \%$ ) and the incomplete (median, $9 \mathrm{~mL}$; range, $3-45 \mathrm{~mL} ; n=4,36 \%$ ) response groups $(P>.05)$.

\section{DISCUSSION}

In this study, we demonstrated that EA could be safely performed without any adverse events and could achieve complete disappearance of ranulas in $45 \%$ of patients at the 6-month follow-up. We also found that EA was significantly more effective and had a significantly higher complete response rate in patients with $\leq 12$ months of symptoms, compared with those with a longer duration of symptoms ( $73 \%$ versus $11 \%$, respectively). Although longterm follow-up results are still unknown, EA could be an alternative nonsurgical approach for patients experiencing symptoms for $\leq 12$ months, given the potential risk of damage to the lingual nerve and the submandibular duct in an operation.

Two studies have previously reported a complete response rate of $52 \%-77 \%{ }^{1,8}$ after chemical ablation of ranulas with OK-432 at a median follow-up of 10-12 months. The studies reported ad- verse events such as early rupture of the ranula (37\%), fever lasting 2-3 days after injection (57\%), injection site swelling for 1 week $(47 \%)$, mild odynophagia $(33 \%)$, and 1 incident of severe swallowing difficulty, which required admission for treatment. ${ }^{1,8}$ Neither of the previous studies correlated the clinical or radiologic characteristics with the treatment outcome or reported the pretreatment duration of symptoms among the enrolled patients.

OK-432 is a lyophilized mixture of a low-virulence strain of group-A Streptococcus pyogenes incubated with benzylpenicillin. ${ }^{2}$ The sclerosing effect of OK-432 retained in the cystic cavity is due to a strong local inflammatory reaction by activated neutrophils and monocytes, which secondarily produce cytokines and induce transient flulike symptoms or early rupture of the treated ranula. In addition, the use of OK-432 is contraindicated in those with penicillin allergy. ${ }^{5,8}$ On the other hand, ethanol acts as a sclerosing agent by instantaneous dehydration of the cyst wall, protein denaturation, clumping of blood cells, and vessel wall necrosis, ${ }^{2}$ which allow us to re-aspirate the injected ethanol after 5-10 minutes of retention. We believe that re-aspiration of the ethanol may reduce the potential for adverse events, such as facial flushing or dizziness, due to systemic absorption of the chemical ablation agent or site swelling or odynophagia from leakage at the injection site.

Another technique that may minimize local complications is the injection of lidocaine into the ranula after aspiration of the thick mucus fluid. We used $2 \%$ lidocaine at half the volume of the aspirate for 30 seconds before the ethanol injection in all cases, first, to check for the presence of the hypoglossal or the lingual nerve and, second, to locally anesthetize the surrounding soft tissues. No motor or sensory changes were noted in any of the patients after lidocaine injection in this study.

To our knowledge, this is the first report to evaluate the efficacy of EA in the treatment of ranulas. Although the overall complete response rate at 6-month follow-up was lower than antici- 
pated, we were able to determine that the duration of symptoms was the only clinicoradiologic factor predicting a better outcome after EA in patients with ranulas. Neither the pretreatment volume nor the parapharyngeal extension was associated with the treatment outcome. Given that ductal disruption by trauma is a major causative factor of ranulas, persistent leakage of mucus fluid might hinder the sealing off of the leaking point with ethanol.

This study has several limitations in addition to its retrospective nature. First, we did not evaluate the long-term follow-up outcome after EA. However, we demonstrated the safety of EA for treating ranulas and described some techniques that may improve its safety. We believe our results could be the basis of promoting further studies with larger groups of patients and longer follow-up periods. Second, our study included 7 patients with a history of prior treatment, including surgery or chemical ablation with OK-432. Because the number of enrolled patients was small, we could not evaluate the potential confounding effects of previous treatments. This should be further investigated in future studies. Last, the sample size of this study was too small to generalize our results, which should be proved with further larger studies.

\section{CONCLUSIONS}

EA is a safe noninvasive treatment technique for ranulas, showing significantly better outcomes in patients with $\leq 12$ months of symptoms. Given the potential risk of damage to the lingual nerve and the submandibular duct during an operation, EA could be considered an alternative nonsurgical approach for patients with symptoms for $\leq 12$ months.

\section{REFERENCES}

1. Roh JL. Primary treatment of ranula with intracystic injection of OK-432. Laryngoscope 2006;116:169-72 CrossRef Medline

2. Kim JH. Ultrasound-guided sclerotherapy for benign non-thyroid cystic mass in the neck. Ultrasonography 2014;33:83-90 CrossRef Medline

3. Patel MR, Deal AM, Shockley WW. Oral and plunging ranulas: what is the most effective treatment? Laryngoscope 2009;119:1501-09 CrossRef Medline

4. Zhao YF, Jia J, Jia Y. Complications associated with surgical management of ranulas. J Oral Maxillofac Surg 2005;63:51-54 Medline
5. Fukase S, Ohta N, Inamura K, et al. Treatment of ranula wth intracystic injection of the streptococcal preparation OK-432. Ann Otol Rhinol Laryngol 2003;112:214-20 CrossRef Medline

6. Woo JS, Hwang SJ, Lee HM. Recurrent plunging ranula treated with OK-432. Eur Arch Otorhinolaryngol 2003;260:226-28 Medline

7. Lee HM, Lim HW, Kang HJ, et al. Treatment of ranula in pediatric patients with intralesional injection of OK-432. Laryngoscope 2006; 116:966-69 Medline

8. Rho MH, Kim DW, Kwon JS, et al. OK-432 sclerotherapy of plunging ranula in 21 patients: it can be a substitute for surgery. AJNR Am J Neuroradiol 2006;27:1090-95 Medline

9. Roh JL, Kim HS. Primary treatment of pediatric plunging ranula with nonsurgical sclerotherapy using OK-432 (picibanil). Int $\mathrm{J} \mathrm{Pe}$ diatr Otorhinolaryngol 2008;72:1405-10 CrossRef Medline

10. Mason KP, Michna E, Zurakowski D, et al. Serum ethanol levels in children and adults after ethanol embolization or sclerotherapy for vascular anomalies. Radiology 2000;217:127-32 CrossRef Medline

11. Gelczer RK, Charboneau JW, Hussain S, et al. Complications of percutaneous ethanol ablation. J Ultrasound Med 1998;17:531-33 CrossRef Medline

12. Kim SM, Baek JH, Kim YS, et al. Efficacy and safety of ethanol ablation for thyroglossal duct cysts. AJNR Am J Neuroradiol 2011;32: 306-09 CrossRef Medline

13. Lee SJ, Ahn IM. Effectiveness of percutaneous ethanol injection therapy in benign nodular and cystic thyroid diseases: long-term follow-up experience. Endocr J 2005;52:455-62 CrossRef Medline

14. Zingrillo M, Torlontano M, Chiarella R, et al. Percutaneous ethanol injection may be a definitive treatment for symptomatic thyroid cystic nodules not treatable by surgery: five-year follow-up study. Thyroid 1999;9:763-67 CrossRef Medline

15. Impellizzeri $P$, Romeo C, Borruto FA, et al. Sclerotherapy for cervical cystic lymphatic malformations in children: our experience with computed tomography-guided $98 \%$ sterile ethanol insertion and a review of the literature. J Pediatr Surg 2010;45:2473-78 CrossRef Medline

16. Baek JH, Ha EJ, Choi YJ, et al. Radiofrequency versus ethanol ablation for treating predominantly cystic thyroid nodules: a randomized clinical trial. Korean J Radiol 2015;16:1332-40 CrossRef Medline

17. In HS, Kim DW, Choo HJ, et al. Ethanol ablation of benign thyroid cysts and predominantly cystic thyroid nodules: factors that predict outcome. Endocrine 2014;46:107-13 CrossRef Medline

18. Koo HJ, Lee JH, Kim GY, et al. Ethanol and/or radiofrequency ablation to treat venolymphatic malformations that manifest as a bulging mass in the head and neck. Clin Radiol 2016;71:1070.e1-7 CrossRef Medline 